Res., Soc. Dev. 2019; 8(8):e09881179

ISSN 2525-3409 | DOI: http://dx.doi.org/10.33448/rsd-v8i8.1179

\title{
A influência da Governança Corporativa na rentabilidade das Instituições Financeiras
}

The influence of Corporate Governance on the profitability of Financial Institutions

La influencia del Gobierno Corporativo en la rentabilidad de las Entidades Financieras

Recebido: 10/05/2019 | Revisado: 16/05/2019 | Aceito: 26/05/2019 | Publicado: 30/05/2019

Ana Luísa Moreira Alves Barbosa

ORCID: https://orcid.org/0000-0002-0985-9431

Faculdade Divinópolis - FACED, Brasil

E-mail: analuisa_m_a_barbosa@hotmail.com

Isabela Lorrayni Deodato Pedreiro

ORCID: https://orcid.org/0000-0001-7314-728X

Faculdade Divinópolis - FACED, Brasil

E-mail: beldeodato4@gmail.com

Laura Oliveira de Souza

ORCID: https://orcid.org/0000-0002-7290-3917

Faculdade Divinópolis - FACED, Brasil

E-mail: laurasouz4@gmail.com

Willian Antônio de Castro

ORCID: https://orcid.org/0000-0001-8742-9018

Centro Universitário - UNA Divinópolis, Brasil

E-mail: willantonio.castro@gmail.com

\section{Resumo}

Este artigo tem como principal objetivo estudar a Governança Corporativa (GC) como determinante de desempenho para as 27 Instituições Financeiras listadas no segmento bancário da Brasil, Bolsa, Balcão (B3) em 2018. Apurando se, estas obtiveram melhores indicadores de rentabilidade, liquidez e mercado ao pertencerem à um dos níveis diferenciados de Governança (Nível 1, Nível 2 ou o Novo Mercado). Segundo Fernandes, Dias e Cunha (2010), e Vinhado (2010), a Governança dentro das Instituições Financeiras diminuiria os conflitos de agência potencializados pelo risco extra que este ramo apresenta, tendo assim, ganhos de performance devido ao rigor das práticas exigidas. Para a análise, coletou-se informações através das demonstrações financeiras: Balanço Patrimonial, Demonstração do Resultado do Exercício, Demonstração de Fluxo de Caixa e Notas 
Explicativas, referentes aos anos de 2010 à 2017. Os indicadores foram calculados anualmente, e classificados em dois grupos: com e sem GC diferenciada. Com o teste de média t-Student, foi testado se há diferença entre as médias de ambos os grupos a um nível de confiança estatística de $95 \%$. Os resultados rejeitam as hipóteses de que pertencer a um dos níveis especiais de GC, garante melhores índices de liquidez e rentabilidade, exceto para a Margem de Lucro que neste caso tem média maior. Contudo, confirmou-se que as empresas possuem melhor performance de mercado ao avaliar o EBITDA. Percebe-se então que os resultados econômicos e financeiros das instituições bancárias não são impactados de forma positiva pela GC, ao contrário da performance de mercado.

Palavras-chave: Governança Corporativa; Contabilidade; Demonstrações Financeiras; Indicadores; Instituição Financeiras.

\section{Abstract}

This article has as main objective to analyze the Corporate Governance (CG) as a determinant of performance for the 27 Financial Institutions listed on the banking segment of Brasil, Bolsa, Balcão (B3) in 2018. Finding out, if these corporations obtained better indicators of profitability, liquidity and market by the fact of being members of the special levels of Corporate Governance (Level 1, Level 2 and New Market). According to Fernandes, Dias and Cunha (2010), and Vinhado (2010), the CG would diminish the agency conflicts that are maximized by the extra risk presented on this segment, and it would also increase their performances seeing the special levels are more burocratic. For analysis, the information were collected through the Balance Sheet, Income Statement, Cash Flow Statement and Explanatory Notes, from 2010 to 2017. All indicators were calculated and classified in two different groups: one with special Corporate Governance, and the other one without it. The hypothesis were tested using the t-Student test, checking if there is difference between the means of the two groups, in a confidence level of $95 \%$. The results refused the hypothesis of that belonging to a Corporate Governance special level guarantees better liquidity and profitability indicators, with the exception of the Profit margin that is higher on this case. However, it was confirmed that companies in the CG special levels have better EBITDA. Therefore, it is concluded that financial and economic results of banking operations are not positively impacted by $\mathrm{CG}$, as opposed to market performance.

Keywords: Corporate Governance; Accountancy; Financial Statements; Financial Indicators; Financial Institutions. 


\section{Resumen}

Este artículo tiene como objetivo estudiar el GC - Gobierno Corporativo como determinante en el desempeño de las 27 entidades financieras listadas en el segmento bancario de la B3 Brasil, Bolsa, Balcão en 2018. Tambíen, se averigua si estas entidades financieras obtuvieron mejores indicadores de rentabilidad, liquidez y mercado al pertenecer a uno de los niveles diferenciados de Gobierno (Nivel 1, Nivel 2 o Nuevo Mercado). Según Fernandes, Dias y Cunha (2010), y Vinhado (2010), el gobierno dentro de las entidades financieras disminuiría los conflictos de agencia potencializados por el riesgo extra que este sector presenta, teniendo ganancias de desempeño debido al rigor de las prácticas exigidas. Para el análisis, se recolectó información a través de: balance patrimonial, demostración de resultado, demonstración de flujo de caja y notas explicativas, referentes a los años de 2010 a 2017. Los indicadores fueron calculados anualmente y clasificados en dos grupos: con y sin GC diferenciada. La prueba de promedio t-Student fue utilizada para evaluar si hay diferencia entre los promedios de ambos los grupos con un nivel de confianza estadística de 95\%. Los resultados rechazan las hipótesis de que pertenecer a uno de los niveles especiales de GC garantiza mejores índices de liquidez y rentabilidad, excepto para el margen de ganancia. Sin embargo, se confirmó que las empresas poseen mejores desempeños de mercado al evaluar el EBITDA. Se percibe entonces que los resultados económicos y financieros de las instituciones bancarias no son impactados favorablemente por el GC, al contrario del desempeño de mercado.

Palabras clave: Gobierno Corporativo; Contabilidad, Muestras Financieras; Indicadores; Instituciones Financieras.

\section{Introdução}

A Governança Corporativa (GC), além de um mecanismo de uso obrigatório para as sociedades de capital aberto, é também uma ferramenta utilizada para melhorar sua atratividade em geral. Alguns estudos como os de Fernandes, Dias e Cunha (2010), e Lima, Araújo e Amaral (2008) evidenciaram que, demonstrar transparência e confiabilidade, gera marketing positivo para as companhias, implicando em um melhor resultado para as mesmas.

O ramo das Instituições Financeiras, por ter uma grande importância na economia, é frequentemente usado como objeto de estudo em diversos contextos e temas. Vinhado (2010) relata como é relevante para este setor reconhecer seus determinantes de desempenho para 
aumentar a eficiência do processo decisório na gestão.

Como problema de pesquisa, foi investigado se instituições financeiras com um nível de governança corporativa diferenciado possuem melhor desempenho financeiro, avaliando as hipóteses de que estes bancos pertencentes ao novo mercado, ou aos níveis 1 e 2 de governança são mais rentáveis, tem mais liquidez, e melhor performance frente a indicadores internacionais de mercado.

Para responder ao questionamento, a pesquisa teve como objetivo principal averiguar se as instituições financeiras com governança corporativa diferenciada e que estão listadas na B3 - Brasil, Bolsa, Balcão, obtiveram melhor rentabilidade e melhores índices financeiros no período de 2010 a 2017. E como objetivos específicos buscou-se: analisar qual o retorno obtido pelas empresas ao investir em governança corporativa, investigando, por exemplo, se nestes casos as ações se tornam mais valorizadas; e, se atender à normatização imposta pela B3 para pertencer a um segmento diferenciado conta como vantagem competitiva no mercado.

Esta pesquisa se justifica por abordar um tema ainda pouco explorado e pelo conhecimento gerado para trabalhos acadêmicos futuros que podem ser aplicados no mercado para demonstrar às instituições financeiras a importância de trabalhar a governança corporativa para atingir melhores resultados por terem informações mais confiáveis e fidedignas. O segmento bancário traz consigo alguns conflitos que podem prejudicar a atuação prática da governança. Um dos principais problemas concerne aos conflitos de agência, como por exemplo, a possibilidade de gerentes enviesarem as escolhas de seus clientes na hora de investir por possuírem informações sobre as empresas a serem investidas. Para as instituições financeiras, aprimorar a prestação de contas além do mínimo exigido pela legislação, focando em transparência e na preservação de interesses de seus diversos públicos através das práticas de governança corporativa, pode influenciar a decisão dos investidores, bem como dos tomadores de crédito e depositantes, assegurando o crescimento e a continuidade das mesmas.

\section{Metodologia}

Para cumprir os objetivos do presente trabalho, foi realizada uma pesquisa documental, ou seja, baseada na análise feita em documentos, que neste caso foram as demonstrações financeiras das instituições bancárias. Trata-se também de uma pesquisa bibliográfica, por se apoiar em publicações literárias científicas previamente publicadas em 
ISSN 2525-3409 | DOI: http://dx.doi.org/10.33448/rsd-v8i8.1179

revistas, livros e outros. Pode-se ser ainda descrita como exploratória, pois busca-se a todo tempo compreender a relação de causa e efeito entre a governança corporativa e o desempenho das instituições financeiras. (Fontenelles, Simões, Farias \& Fontenelles, 2009)

Por fim, classifica-se esta pesquisa como quantitativa por ser uma análise de dados numéricos. Segundo Pereira, Shitsuka, Parreira \& Shitsuka (2018), informações quantitativas, são frequentemente avaliados através de metodologias matemáticas, como a estatística por exemplo. Para Terence e Escrivão Filho (2006), o uso de parâmetros quantitativos pode ser aplicado a situações que permitem ser tratadas com objetividade, obtedo resultados exatos, reprodutíveis e generalizáveis.

As informações que compõem a amostra referem-se a índices de liquidez, rentabilidade e desempenho operacional calculados através das demonstrações financeiras (notas explicativas, balanço patrimonial, demonstração de resultado do exercício, demonstração de fluxo de caixa - DFC) das 27 Instituições financeiras listadas na B3 em abril de 2018 conforme a Tabela 1.

Tabela 1: Instituições Financeiras Listadas na B3 em abril de 2018

\begin{tabular}{c|l}
\hline \multicolumn{2}{l}{ INSTITUIÇÕES FINANCEIRAS LISTADAS NA B3 EM ABRIL DE 2018 } \\
\hline 1 & ABC BRASIL \\
\hline 2 & ALFA \\
\hline 3 & AMAZÔNIA \\
\hline 4 & BANCO DO NORDESTE \\
\hline 5 & BANCO PANAMERICANO \\
\hline 6 & BANESE \\
\hline 7 & BANESTES \\
\hline 8 & BANK AMERICA \\
\hline 9 & BANPARA \\
\hline 10 & BANRISUL \\
\hline 11 & BRADESCO \\
\hline 12 & BANCO DO BRASIL \\
\hline 13 & BRB BANCO \\
\hline 14 & BTGP BANCO \\
\hline 15 & CITIGROUP \\
\hline 16 & GOLDMANSACHS \\
\hline 17 & INDUSVAL \\
\hline 18 & ITAU S/A \\
\hline 19 & JPMORGAN \\
\hline 20 & MERCANTIL DO BRASIL \\
\hline 21 & PARANA \\
\hline 22 & PATAGONIA \\
\hline 23 & PINE \\
\hline
\end{tabular}


Fonte: Dados da pesquisa.

\begin{tabular}{l|l}
24 & SANTANDER \\
\hline 25 & UBS GROUP \\
\hline 26 & US BANCORP \\
\hline 27 & WELLS FARGO \\
\hline
\end{tabular}

O período de análise compreende os anos de 2010 a 2017 e são separados em dois grupos diferentes: instituições financeiras que estão listadas em algum nível diferenciado de GC e instituições financeiras que não possuem governança corporativa diferenciada.

Abaixo, apresenta-se o Quadro 1 que expõe anualmente a amostra de empresas com e sem governança corporativa diferenciada:

QUADRO 1 - QUANTIDADE DE EMPRESAS COM E SEM GOVERNANÇA CORPORATIVA DIFERENCIADA POR ANO PESQUISADO.

\begin{tabular}{|c|c|c|}
\hline \multicolumn{3}{|c|}{ INSTITUIÇÕES FINANCEIRAS } \\
\hline ANO & COM GC DIFERENCIADA & SEM GC DIFERENCIADA \\
\hline 2010 & 8 & 19 \\
\hline 2011 & 8 & 19 \\
\hline 2012 & 9 & 18 \\
\hline 2013 & 9 & 18 \\
\hline 2014 & 9 & 18 \\
\hline 2015 & 8 & 19 \\
\hline 2016 & 8 & 19 \\
\hline 2017 & 8 & 19 \\
\hline
\end{tabular}

Fonte: Dados da pesquisa.

Observa-se que no período referenciado no Quadro 1, há raras alterações nas quantidades de empresas que pertencem ou não a um nível diferenciado de governança corporativa.

A partir da coleta de dados, os resultados dos indicadores calculados serão reagrupados conforme o nível de governança corporativa diferenciada (N1, N2 e NM) ou sem governança corporativa diferenciada, e, assim, aplica-se o teste de hipótese t-Student utilizando o software Stata®.

Segundo Silva (2014) “o teste t-Student é aplicado quando pretende-se comparar as médias de uma variável quantitativa em dois ou mais grupos diferentes e dos quais se desconhecem a variância”. Ainda segundo Silva (2014), neste tipo de teste são utilizadas duas amostras independentes. Para análise dos dados através do teste t, nesta pesquisa, foi utilizado 
o nível de significância de 5\%, e um P-valor (nível de confiança estatística) de 95\%. O resultado obtido permite avaliar se existe uma relação estatística entre governança corporativa e bom desempenho econômico e financeiro.

\section{Governança Corporativa}

Segundo Silva (2010) a Governança Corporativa é um modelo de gestão que, através de um planejamento estratégico estrutural, busca otimizar processos que protegem de forma equitativa os sócios e acionistas que avançam no mercado com a finalidade de buscar seus objetivos com transparência e veracidade através da prestação de contas aos acionistas e outras partes interessadas.

Podendo assim ser assim definida:

Governança corporativa é o modelo de gestão que, a partir da otimização das interações entre acionistas ou cotistas, Conselhos - de administração e Fiscal, Auditorias Externa e Interna e Diretoria Executiva, proporciona a adequada sustentação para o aumento da atratividade da empresa no mercado - Financeiro e Comercial - e, consequentemente, incremento no valor da empresa, redução do nível de risco e maior efetividade da empresa ao longo do tempo. (Oliveira, 2006, p. 9).

Ou seja, a Governança é de suma importância para garantir o funcionamento das operações e processos dentro de uma organização de forma a reduzir a possibilidade de ocorrências fraudulentas que além dos acionistas, vem a prejudicar outros públicos como funcionários e clientes, consequentemente impactando a economia.

Ainda conforme Oliveira (2006), sabe se que a governança originou de um tripé composto pelo fundo LEANS, relatório Cadbury e pelos princípios da OCDE e o filtro básico do processo corresponde à Lei Sarbanes-Oxley. O fundo de investimento LEANS é um novo modelo de gestão que proporciona melhores resultados para as empresas. Ele se baseia em melhores atuações, monitoramento eficaz e sustentações fortes através da ética empresarial. Além disso, a ética está diretamente relacionada aos resultados da empresa, organizações modernas complexas e dinâmicas, geradoras de fortuna na qual realizar investimentos é a base de sustentação e desenvolvimento das empresas. Quanto ao relatório de Cadbury, ele foca na constituição e estruturação do Conselho de Administração (principal órgão interno de boa condução da empresa) evidenciando a atuação, responsabilidade e remuneração dos 
conselheiros.

A Organização de Cooperação e de Desenvolvimento Econômico (OCDE) contribui para a Governança Corporativa, pois determina que a Governança tem o dever de proteger os direitos dos acionistas, tendo tratamento igualitário e equitativo, exigindo transparência e veracidade nas informações disponibilizadas em geral. Uma vez que todos os fatos relevantes devem ser prontamente divulgados ao público interessado, as responsabilidades e as atuações do conselho de administração devem estar claras, compreendidas e avaliadas.

Após uma série de escândalos ocorridos nas maiores organizações do mercado de capital norte-americano, a Governança corporativa foi o principal foco de análise das organizações pela gestão e resultados obtidos. Assim, os congressistas Paul Sarbanes e Michael Oxley criaram a Lei Sarbanes-Oxley, conhecida como Lei Sox, que, com a crise financeira, foi considerada a maior reforma de mercado de capital americano, mas que impacta organizações de capital aberto no mundo todo. O objetivo é minimizar fraudes contábeis que influenciam no desempenho financeiro das organizações, exigindo a transparência e fidedignidade das informações prestadas. Busca recuperar a credibilidade e selecionar no mercado as empresas com maior confiabilidade, protegendo assim os atuais e futuros investidores. (Silva, 2010)

\section{Níveis diferenciados de Governança Corporativa}

Foi criada pela B3 em dezembro de 2000 os Níveis Diferenciados e o Novo Mercado de Governança Corporativa com o intuito de fornecer a interação dos investidores e companhias com seus respectivos interesses. Estabeleceu um protótipo diferenciado de Governança Corporativa, no qual, para se encaixar no Novo Mercado ou nos Níveis diferenciados, é necessário cumprir algumas obrigações exigidas, (B3, 2016).

Os níveis de Governança Corporativa são uma forma de avaliar o investimento nestas empresas, sendo um diferencial em meio a tantas alternativas, pois agrega importância em uma análise mais completa e realista, (B3, 2016).

A partir do momento em que uma empresa adota níveis diferenciados de Governança, automaticamente gera vantagem competitiva em relação às outras empresas, fornecendo mais exatidão e confiabilidade às informações contábeis, uma vez que as mesmas estão dispostas a cumprir obrigações que vão além das já exigidas. Assim, fornece informações que agregam tanto para os acionistas quanto para as empresas no mercado, (Trading Bolsa, 2018).

Os segmentos especiais de GC oferecidos pela B3 são: 
Res., Soc. Dev. 2019; 8(8):e09881179

ISSN 2525-3409 | DOI: http://dx.doi.org/10.33448/rsd-v8i8.1179

- Novo Mercado: estabelece um padrão elevado de Governança e seu diferencial é poder emitir apenas ações ordinárias (são ações com direito a voto).

- Nível 1: visa as boas práticas da GC, com enfoque na transparência e dispersão acionária (distribuição das ações para pessoas diferentes). É permitido emitir ações ordinárias e preferenciais.

- Nível 2: É superior ao Nível 1, com práticas mais rígidas e burocráticas. Exige transparência e dispersão acionária, sendo necessário manter o equilíbrio de direitos entre acionistas controladores e minoritários.

\section{Governança nas Instituições Financeiras}

Para Nassiff e Souza (2013) os conflitos de agência podem surgir entre acionistas e gestores, pois, por diversas vezes, os pontos de vista dos gestores não correspondem aos dos acionistas por possuírem visões diferentes de mercado, ocasionando conflitos internos que prejudicam os resultados e o desempenho da empresa. Tais conflitos de agência também ocorrem entre acionistas majoritários e acionistas minoritários devido ao poder de voto. Há também, conflitos de agência entre executivos e proprietários por problemas com remuneração, autoridade, autonomia e submissão. Assim, os executivos possuem acesso a informações privilegiadas e tendem a privilegiar as próprias ações em detrimento dos objetivos da empresa.

O setor financeiro, por possuir várias particularidades de risco, é um dos mais regularizados no Brasil e no mundo, pois prioriza as boas práticas, diminuindo os riscos para partes interessadas e adota um modelo de Governança Corporativa que desenvolva uma gestão estratégica para melhores resultados com segurança.

O conjunto das boas práticas, o gerenciamento e o controle interno dos riscos contribuem para o fortalecimento de suas estruturas de governança, sendo fundamental para o desenvolvimento da mesma, além da confiança e credibilidade no mercado. (Sant'Anna, 2015)

\section{6. Índice de Governança Corporativa (IGC) e Indicadores}

O Índice de Governança Corporativa (IGC) foi criado pela B3 em 2001. É um índice de retorno total com o objetivo de avaliar os diferentes níveis de Governança Corporativa através do desempenho da carteira de ações de empresas listadas no Novo Mercado ou nos 
Níveis 1 ou 2 da B3. O objetivo é entender se os resultados dos índices impactam nos valores dos ativos, trazendo resultados financeiros relevantes ou se impactam apenas nas boas práticas, proporcionando melhor gestão na empresa, porém, sem nenhum ganho financeiro significativo. (B3, 2015)

O IGC pode ser calculado da seguinte maneira:

$$
\begin{aligned}
& \mathrm{IGC}_{\mathrm{t}}=\mathrm{IGC}_{\mathrm{t}-1} * \sum_{\mathrm{i}-1}^{\mathrm{m}} \mathrm{Qi} \quad \mathrm{t}-1 * \mathrm{Pi}_{\mathrm{t}} \\
& \sum_{\mathrm{i}-1}^{\mathrm{m}} \mathrm{Qi} \quad \mathrm{t}-1 * \mathrm{Pi}_{\mathrm{t}}
\end{aligned}
$$

Onde:

$\operatorname{IGC}(\mathrm{t})=$ valor do índice no dia $\mathrm{t}$; IGC $(\mathrm{t}-1)=$ valor do índice no dia $\mathrm{t}-1$;

$\mathrm{n}=$ número de ações integrantes da carteira teórica do índice;

Qit-1 = quantidade teórica da ação i disponível à negociação no dia t-1. Na ocorrência da distribuição de proventos em ações do mesmo tipo pela empresa, refere-se à quantidade teórica da ação i disponível à negociação no dia $\mathrm{t}-1$, recalculada em função deste provento;

Pit = preço da ação i no fechamento do dia t;

Pit-1 = preço de fechamento da ação i no dia t-1, ou seu preço ex-teórico, no caso da distribuição de proventos nesse dia. (Santos \& Pedreira, 2004, p. 91)

\section{Indicadores}

Avaliar os resultados dos processos é essencial para a sobrevivência de qualquer empresa. Para Oliveira (1990), a aplicação do feedback é uma forma de corrigir falhas identificadas em diferentes processos que compõem a estrutura organizacional, aumentando a eficiência da empresa. Esta mesma ideia pode ser aplicada às práticas de governança, bem como na interpretação dos resultados econômico-financeiros, compreendendo os possíveis motivos e consequências dos mesmos nos valores expressos nas demonstrações.

Usa-se comumente indicadores para mensurar o desempenho de empresas como podese observar em Ribeiro (2017), Fernandes et al (2010) e Bortoluzzi, Ensslin, Ensslin e Chaves (2014).

6.1 Indicadores de Rentabilidade 
Algumas das principais variáveis para medir o desempenho de uma corporação através de seus relatórios contábeis é a rentabilidade, que, segundo Padoveze e Benedicto (2010), abarca a interação entre giro e margem. Para analisar tal relação, será usado o seguinte índice: O Retorno sobre o Ativo (ROA - Return on Assets), que, de acordo com Vieira, Verde, Bezerra, Rodrigues e Ismael (2011), possibilita o conhecimento do retorno obtido com base nas aplicações feitas no Ativo.

$$
\text { ROA = LUCRO LÍQUIDO / ATIVO MÉDIO }
$$

O Ativo também será avaliado pelo enfoque de rotatividade, chegando à quantidade de vezes em que o ativo girou para atingir tal receita líquida de vendas (RLV). (Padoveze \& Benedicto, 2010)

\section{GIRO DO ATIVO = RLV / ATIVO MÉDIO}

Para Martins (2005), o Retorno sobre o Patrimônio Líquido (ROE - Return on Equity), demonstra se a entidade em questão é uma boa opção de investimento, através da taxa de retorno sobre o capital próprio (Patrimônio Líquido).

\section{ROE = LUCRO LÍQUIDO / PATRIMÔNIO LÍQUIDO MÉDIO}

Por fim, temos a Margem de Lucro, que segundo Lameira (2005), indica qual o percentual da Receita Líquida de Vendas sobrou após deduzir todas as despesas e impostos.

\section{MARGEM DE LUCRO = LUCRO LÍQUIDO / RECEITA LÍQUIDA DE VENDAS}

\subsection{Indicadores de Liquidez}

O desempenho das instituições financeiras também será medido através dos índices de liquidez que trata da parcela de obrigações que consegue ser suprida pelas disponibilidades, principalmente as contas de curto prazo do passivo circulante, (Marion, 2007; Soares, Lyra, Hein \& Kroenke, 2011). 
Neste estudo, será usado o índice de Liquidez Corrente - LC e o índice de Liquidez Geral - LG. O primeiro trata da proporção dos ativos de curto prazo (AC) para os passivos de curto prazo (PC), e o segundo, calcula tal proporção sobre os ativos e passivos totais. Será positivo para a empresa quando o resultado de ambos os índices for superior a 1, pois implica que os ativos são o bastante para cobrir suas dívidas, (Matarazzo, 2008).

$$
\begin{aligned}
& \text { LC }=\mathbf{A C} / \mathbf{P C} \\
& \text { LG }=\text { ATIVO } / \text { PASSIVO }
\end{aligned}
$$

\subsection{Indicadores de Mercado}

Desde a consolidação do plano real, aumentou-se uma série atividades dentro do setor financeiro. Segundo Paula, Oreiro e Basílio (2013), como consequência, houve uma diversificação do mercado, levando os bancos públicos a perderem força em função do surgimento dessas novas instituições.

Estas novos bancos aos pouco foram dominando a clientela, devido a oferta de novos produtos e serviços, com taxas e prazos diferenciados atendendo diversas necessidades das pessoas e empresas, contribuindo para a alta competitividade do setor.

Na visão de Lima et al (2008), esta diversificação do ramo, somada a outros acontecimentos como a globalização, o crescimento da economia mundial entre outros, amplificaram os efeitos das relações entre instituição, acionistas e investidores.

Afinal, nota-se que viver nesta sociedade globalizada, somado aos avanços da tecnologia, e com a expectativa de vida maior da população gera a necessidade de se ter e consumir mais, e também de planejar melhor o futuro. Por isso o maior interesse em descobrir métodos melhores e mais práticos de lidar com dinheiro, o que aproximou bancos e pessoas.

Diante disso, procurando compreender melhor o funcionamento e a dinâmica desse setor, será avaliado o desempenho, e, a eficiência operacional será mensurada pelo EBITDA (Earns Before Interest, Taxes, Depreciation and Amortization) ou LAJIDA (Lucro antes dos Juros, Impostos, Depreciação e Amortização), que, para Coelho (2004), trata-se de uma verificação mais profunda dos resultados provenientes da operação principal da empresa, já que em tal análise desconsidera as despesas financeiras, de Amortização e Depreciação e tributos recolhidos.

\section{Resultados e Discussões}


ISSN 2525-3409 | DOI: http://dx.doi.org/10.33448/rsd-v8i8.1179

Para responder ao problema da presente pesquisa, os dados foram agrupados em duas amostras distintas. A primeira com dados das instituições financeiras que possuem Governança Corporativa diferenciada (N1, N2 e NM), e a segunda com as instituições financeiras que não possuem Governança Corporativa diferenciada.

Primeiro foi testada a hipótese de que Instituições Financeiras com GC diferenciada possuem melhores indicadores de rentabilidade. Os resultados são demonstrados através das médias dos indicadores Retorno sobre o Ativo, Retorno sobre o Patrimônio Líquido, Giro do Ativo e Margem de Lucro.

Segue abaixo o Quadro 2, onde são apresentados os dados relacionados as médias dos grupos com e sem governança corporativa diferenciada em relação ao Indicador Retorno sobre o Ativo - ROA:

\section{QUADRO 2 - TESTE DE DIFERENÇA DE MÉDIA - ROA}

\begin{tabular}{|l|r|l|l|}
\hline \multicolumn{4}{|c|}{ Retorno sobre Ativo - ROA } \\
\hline Grupo & \multicolumn{1}{|l|}{ Obs. } & Média & Erro Padrão \\
\hline Com Governança Corporativa Diferenciada & 67 & .0127251 & .0029456 \\
\hline Sem Governança Corporativa Diferenciada & 45 & .0165822 & .0019505 \\
\hline Diferença & & -.0038571 & .0034988 \\
\hline Ha: Diferença das médias = & \multicolumn{2}{|l|}{$\operatorname{Pr}(|\mathrm{T}|>|\mathrm{t}|)=0.2715$} \\
\hline
\end{tabular}

Fonte: Dados da pesquisa.

Os resultados demonstrados no Quadro 2 demonstram que, com um nível de significância de 5\%, as médias do ROA de empresas com Governança Diferenciada e empresas sem Governança Diferenciada são diferentes. E a média do ROA das empresas sem Governança é maior que a média do ROA das empresas que possuem Governança.

A seguir, no Quadro 3 observa-se a relação entre as médias dos dois grupos analisados em relação ao Indicador Retorno sobre o Patrimônio líquido:

\section{QUADRO 3 - TESTE DE DIFERENÇA DE MÉDIA - ROE}

\begin{tabular}{|l|r|l|c|}
\hline \multicolumn{4}{|c|}{ Retorno sobre Patrimônio Líquido - ROE } \\
\hline Grupo & Obs. & Média & Erro Padrão \\
\hline Com Governança Corporativa Diferenciada & 49 & .1107159 & .0189895 \\
\hline Sem Governança Corporativa Diferenciada & 145 & .131347 & .0097041 \\
\hline Diferença & & -.020631 & .020006 \\
\hline Ha: Diferença das médias = 0 & \multicolumn{2}{|l|}{ Pr(T > t) $=0.3037$} \\
\hline
\end{tabular}

Fonte: Dados da pesquisa. 
ISSN 2525-3409 | DOI: http://dx.doi.org/10.33448/rsd-v8i8.1179

Os dados contidos no Quadro 3 demonstram que, para um nível de significância de $5 \%$, há diferença entre as médias do ROE das instituições com Governança diferenciada e sem Governança diferenciada. Sendo que, a média do ROE do grupo com instituições sem Governança diferenciada é maior do que a média do grupo que possui Governança diferenciada.

Em sequência, apresenta-se o Quadro 4, onde verifica-se a relação entre as médias dos dois grupos em relação ao Indicador Margem de Lucro:

\section{QUADRO 4 - TESTE DE DIFERENÇA DE MÉDIA - ML}

\begin{tabular}{|l|r|l|l|}
\hline \multicolumn{4}{|c|}{ Margem de Lucro } \\
\hline Grupo & \multicolumn{1}{|l|}{ Obs. } & Média & Erro Padrão \\
\hline Com Governança Corporativa Diferenciada & 67 & .3802738 & .12015 \\
\hline Sem Governança Corporativa Diferenciada & 148 & .0770907 & .17999 \\
\hline Diferença & & .3031831 & .2797217 \\
\hline Ha: Diferença das médias = 0 & $\operatorname{Pr}(|\mathrm{T}|>|\mathrm{t}|)=0.2796$ \\
\hline
\end{tabular}

Fonte: Dados da pesquisa.

No Quadro 4, são apresentados os resultados obtidos para ambos os grupos em relação à Margem de Lucro. Ficou demonstrado que, considerando um nível de significância de 5\%, as médias de ML para os grupos são diferentes. E, ao contrário dos outros indicadores de rentabilidade, constata-se que a média de ML para o grupo de empresas com Governança diferenciada é superior àquelas que não participam de algum nível de GC diferenciada da B3.

Em seguida, no Quadro 5 observa-se a relação entre as médias dos grupos estudados comparados ao Indicador Giro do Ativo:

\section{QUADRO 5 - TESTE DE DIFERENÇA DE MÉDIA - GA}

\begin{tabular}{|l|r|l|l|}
\hline \multicolumn{4}{|c|}{ Giro do Ativo - GA } \\
\hline Grupo & \multicolumn{1}{|l|}{ Obs. } & Média & Erro Padrão \\
\hline Com Governança Corporativa Diferenciada & 67 & .0418612 & .0046916 \\
\hline Sem Governança Corporativa Diferenciada & 148 & .0527317 & .0036746 \\
\hline Diferença & & -.0108705 & .0063097 \\
\hline Ha: Diferença das médias $=0$ & \multicolumn{2}{|c|}{$\operatorname{Pr}(|\mathrm{T}|>|\mathrm{t}|)=0.0864$} & \\
\hline
\end{tabular}

Fonte: Dados da pesquisa.

Os resultados apontados no Quadro 5 mostram que, para um nível de significância de $5 \%$, as médias do GA de empresas com Governança Diferenciada e empresas sem 
Governança Diferenciada são diferentes. E a média do GA das empresas sem Governança é maior que a média do GA das empresas que possuem Governança.

Ficou demonstrado que existem diferenças entre as médias para todos os indicadores de rentabilidade testados considerando um nível de significância de 5\%. Na maioria dos casos, nota-se melhor desempenho para o grupo de empresas sem GC diferenciada, com exceção da Margem de Lucro, onde a performance é melhor para instituições com GC diferenciada. Assim, a hipótese anterior é rejeitada parcialmente, pois, apesar de a participação em um nível diferenciado de GC não impactar de modo positivo no Retorno sobre Ativo, Retorno sobre o Patrimônio Líquido e no Giro do Ativo, apresenta influência positiva na média da Margem de Lucro.

Os resultados que respondem à segunda hipótese de que Instituições Financeiras com GC diferenciada têm melhores indicadores de liquidez, estão apresentados a seguir nos quadros 6 e 7.

\section{QUADRO 6 - TESTE DE DIFERENÇA DE MÉDIA - LIQUIDEZ CORRENTE}

\begin{tabular}{|l|r|r|r|}
\hline \multicolumn{5}{|c|}{ Liquidez Corrente LC } \\
\hline Grupo & \multicolumn{1}{|l|}{ Obs. } & \multicolumn{1}{l|}{ Média } & \multicolumn{1}{c|}{ Erro Padrão } \\
\hline Com Governança Corporativa Diferenciada & 67 & .9782979 & .0443046 \\
\hline Sem Governança Corporativa Diferenciada & 148 & 1.083886 & .0412936 \\
\hline Diferença & & -.1055879 & .0682633 \\
\hline Ha: Diferença das médias $=0$ & $\operatorname{Pr}(|\mathrm{T}|>|\mathrm{t}|)=0.1234$ \\
\hline
\end{tabular}

Fonte: Dados da pesquisa.

No Quadro 6, os resultados comprovam que com um nível de significância de 5\%, existe diferença entre as médias de LC das empresas com GC diferenciada e empresas sem GC diferenciada. Sendo que a média do índice de Liquidez Corrente do segundo grupo é maior que a média daquelas instituições com Governança diferenciada.

QUADRO 7 - TESTE DE DIFERENCA DE MÉDIA - LIQUIDEZ GERAL

\begin{tabular}{|l|r|l|l|}
\hline \multicolumn{4}{|c|}{ Liquidez Geral LG } \\
\hline Grupo & \multicolumn{1}{|l|}{ Obs. } & Média & Erro Padrão \\
\hline Com Governança Corporativa Diferenciada & 67 & 1.122365 & .005307 \\
\hline Sem Governança Corporativa Diferenciada & 148 & 1.320191 & .0503194 \\
\hline Diferença & & -.1978258 & .0749681 \\
\hline Ha: Diferença das médias =0 & \multicolumn{2}{|l|}{$\operatorname{Pr}(|\mathrm{T}|>|\mathrm{t}|)=0.0089$} \\
\hline
\end{tabular}

Fonte: Dados da pesquisa. 
Os resultados dispostos no Quadro 7 evidenciam que as médias de LG dos grupos com Governança diferenciada e sem Governança diferenciada são diferentes para um nível de significância de 5\%. E apresentam maior média de LG o grupo de empresas sem GC diferenciada.

Analisando os dados dos Quadros 6 e 7, rejeita-se também a segunda hipótese, pois utilizando um nível de significância de 5\%, as médias dos grupos com e sem GC diferenciada são distintas. E que o fato de pertencer a um segmento especial de Governança não impacta em melhores índices de liquidez.

Finalmente, apresenta-se o Quadro 8 onde foi testada a relação entre o desempenho de mercado através do Indicador EBITDA nos grupos com e sem governança corporativa diferenciada:

QUADRO 8 - TESTE DE DIFERENÇA DE MÉDIA - EBITDA
\begin{tabular}{|l|lr|l|l|}
\hline \multicolumn{5}{|c|}{ EBITDA } \\
\hline Grupo & Obs. & Média & Erro Padrão \\
\hline $\begin{array}{l}\text { Com Governança Corporativa } \\
\text { Diferenciada }\end{array}$ & & 67 & 337.2297 & 1.122 .109 \\
\hline Sem Governança Corporativa Diferenciada & & 148 & 9.271324 & 2.367 .601 \\
\hline Diferença & & & 327.9584 & 75.36691 \\
\hline
\end{tabular}

Fonte: Dados da pesquisa.

No Quadro 8, os dados apresentados mostram que há grande diferença entre as médias de EBITDA dos grupos com Governança diferenciada e sem Governança diferenciada, isto, para um nível de significância de 5\%. Também se constata que o grupo de companhias com Governança diferenciada teve uma performance melhor, tratando-se de EBITDA do que aquelas que não possuem. Portanto, a hipótese de que Instituições Financeiras com GC diferenciada teriam melhores indicadores internacionais de mercado foi comprovada.

\section{Considerações Finais}

Os resultados obtidos através desta pesquisa contribuem para todos os públicos interessados no ramo financeiro, auxiliando a compreender alguns aspectos da relação entre as instituições bancárias e seus acionistas, e de que forma a governança corporativa pode afetála. Além disso, as implicações acerca da performance econômica, financeira e de mercado das 
instituições são de grande serventia para aqueles interessados em compreender melhor o funcionamento deste setor.

A pesquisa desenvolvida apresenta como problemática avaliar se as instituições financeiras com um nível de governança corporativa diferenciada possuem melhor desempenho financeiro através dos indicadores de rentabilidade, mercado e liquidez, foram coletadas informações das instituições financeiras listadas na B3, no período de 2010 a 2017. Para testar as hipóteses do trabalho, aplicou-se o teste de média t-Student através da classificação das empresas em dois grupos: um com as empresas que estão listadas em um nível de GC diferenciada e outro com empresas sem GC diferenciada.

Em todas as análises dos indicadores, os resultados evidenciam que há diferença entre as médias de ambos os grupos, considerando um nível de significância de 5\%. As empresas que possuem GC diferenciada apresentam melhor performance, com média de valores maior apenas para o EBITDA e para a Margem de Lucro. Para os demais indicadores: ROA, ROE, Giro do Ativo, Liquidez Corrente e Geral, as empresas sem governança corporativa diferenciada possuem médias maiores.

De modo geral, esta pesquisa não comprova que os Níveis Diferenciados de Governança Corporativa da B3, influenciam positivamente o desempenho das empresas do segmento bancário, exceto para o EBITDA e para a Margem de Lucro. Portanto, a GC não é um diferencial perante os resultados financeiros, apenas uma melhoria de processos internos que contribui para o bom funcionamento da mesma, na qual tem suas particularidades na qualidade de gestão e desenvolvimento nas boas práticas, descentralizando a tomada de decisão, além de promover uma melhoria da imagem da instituição e valorização da marca.

Estudos futuros podem avaliar a influência da Governança na valorização e volume de negócios das instituições financeiras. Sugere-se também o aumento da amostra com empresas de outros segmentos e com um número maior de anos.

\section{Referências}

B3 2015. Índice de Governança Diferenciada (IGC). Metodologia do IGC. Disponível em: http://www.b3.com.br/pt_br/market-data-e-indices/indices/indices-de-governanca/indice-deacoes-com-governanca-corporativa-diferenciada-igc.htm

B3 2016. Regulamento de Listagem do Nível 1. Disponível em: http://www.b3.com.br/data/files/B8/C5/5D/71/C6E3861012FFCD76AC094EA8/Regulament o\%20de\%20Listagem\%20do\%20N\%C3\%ADvel\%201\%20(San\%C3\%A7\%C3\%B5es\%2020 19).pdf 
B3 2016. Regulamento de Listagem do Nível 2. Disponível em:

http://www.b3.com.br/data/files/1B/B5/A5/87/46E3861012FFCD76AC094EA8/Regulamento \%20de\%20Listagem\%20do\%20N\%C3\%ADvel\%202\%20(San\%C3\%A7\%C3\%B5es\%20201 9).pdf

B3 2016. Regulamento do Novo Mercado. Disponível em:

http://www.b3.com.br/data/files/B7/85/E6/99/A5E3861012FFCD76AC094EA8/Regulamento $\% 20$ do\%20Novo\%20Mercado\%20-

$\% 2003.10 .2017 \% 20($ Sancoes\%20pecuniarias\%202019).pdf

Bortoluzzi, S.C., Ensslin, S.R., Ensslin, L. \& Chaves, L.C. (2014). Indicadores de Desempenho Propostos em Pesquisas Nacionais e Internacionais para Avaliar Redes de Pequenas e Médias Empresas (PMEs). Revista Espacios. Vol. 35, n². P. 17. Disponível em: http://www.revistaespacios.com/a14v35n02/14350218.html

Coelho, F.S. (2004). EBITDA: a busca de uma melhor compreensão do maior vox Populi do mercado financeiro. Prêmio Contador Geraldo de La Rocque, abr.2004. Disponível em: $<$ http://www.atena.org.br/revista/ojs-2.2.3-

06/index.php/pensarcontabil/article/viewFile/66/66>

Crespo, A.A. (2009). Estatística Fácil. 19ª ed. atual., São Paulo, SP. Ed. Saraiva.

Fernandes, N.A. C., Dias, W.O. \& Cunha, J.V.A. (2010). Governança Corporativa no contexto brasileiro: um estudo do desempenho das companhias listadas nos níveis da $B M \& F B O V E S P A$. Organizações em Contexto, 11(1):22-44

Fontenelles, M.J., Simões, M.G., Farias, S.H. \& Fontenelles R.G.S. (2009). Metodologia da pesquisa científica: Diretrizes para a elaboração de um protocolo de pesquisa. UNAMA, Belém/PA. Disponível em:

<https://cienciassaude.medicina.ufg.br/up/150/o/Anexo_C8_NONAME.pdf>

Gil, A.C. (2008). Como elaborar projetos de pesquisa. São Paulo, SP. Atlas.

Lameira, V. (2005). (Coord) Negócios em Bolsa de Valores. São Paulo: Alaúde Editorial.

Lima, R. E.A., Amaral, M. B. V. \& Hudson, F. (2008). Conflitos de Agência: Um estudo comparativo dos aspectos inerentes a Empresas Tradicionais e Cooperativas de Crédito, Identidade, Valores e Governança das Cooperativas. V Encontro de Pesquisadores Latinoamericanos de Cooperativismo. Ribeirão Preto, SP.

Marion, J.C. (2007). Contabilidade Básica, $8^{a}$ Ed, São Paulo, SP. Atlas.

Martins, E. (2005). Análise crítica de balanços - Parte 1. Boletim IOB. Temática Contábil e Balanços. Bol. 26. 
Matarazzo, D.C. (2008). Análise Financeira de Balanços, Abordagem Básica e Gerencial. $6^{\mathrm{a}}$ Ed, São Paulo, SP. Atlas.

Nassiff, E., Souza, C.L. (2013). Conflitos de agencia e governança corporativa. Caderno de administração. Revista do departamento de administração da FEA - PUC (Pontifícia Universidade Católica de São Paulo). São Paulo. Vol. 7. n.1. Jan - Dez, p. 01 - 20

Níveis de Governança Corporativa - Entenda a importância. Trading Bolsa. 2018. Disponível em: <https://www.investimentonabolsa.com/2014/12/niveis-de-governancacorporativa.html $>$.

Oliveira, D.P.R. (2006). Governança Corporativa na Prática: integrando acionistas, conselho de administração e diretoria executiva na geração de resultados. São Paulo. Atlas.

Oliveira, D.P.R. (1990). Sistemas, organização \& métodos: uma abordagem gerencial. 4 ed. São Paulo. Atlas.

Padoveze, C.L.B., \& Gideon, C. (2010). Análise das Demonstrações Financeiras. 3. ed. São Paulo. Cengage Learning.

Paula, L.F., Oreio, J.L. \& Basilio, F. A.C. (2013). Estrutura do Setor bancário e o ciclo recente de expansão do crédito: O papel dos bancos públicos federais. Nova Economia. Belo Horizonte. Minas Gerais. v.23, n. 3, set./dez.

Pereira, A.S., Shitsuka, D.M., Parreira, F.J. \& Shitsuka, R. (2018). Metodologia da pesquisa científica. Editora UAB/NTE/UFSM, Santa Maria/RS. Disponível em:

http://repositorio.ufsm.br/bitstream/handle/1/15824/Lic_Computacao_Metodologia-PesquisaCientifica.pdf?sequence $=1$

Ribeiro, J.F. (2017). Gerenciamento de resultados e indicadores de desempenho em empresas brasileiras de capital aberto. UEPB - Universidade Estadual da Paraíba. Campina Grande, PB.

Sant'ana, F.A.M. (2015). A importância da governança corporativa para as instituições financeiras. IBRACON Instituto dos auditores independentes do Brasil. Disponível em: <www.ibracon.com.br/ibracon/Portugues/detSalaImprensaRelease.php?cod=2473> .

Santos, J.O. \& Pedreira, E.B. (2004). Análise da relação entre o índice de governança corporativa e o preço das ações de empresas do setor de papel e celulose. Administração em Diálogo - PUC (Pontifícia Universidade Católica de São Paulo), São Paulo. v.6, p. 87-99

Soares, M., Lyra, R.L.W. C., Hein, N. \& Kroenke, A. (2011). O emprego da análise de balanços e métodos estatísticos na área pública: o ranking de gestão dos municípios catarinenses. Revista de Administração Pública - Escola Brasileira de Administração Pública e de Empresas. Rio de Janeiro, Brasil. Vol. 45. No 5. Sep./ Out. pp. 1425-1443.

Disponível em:

<http://www.scielo.br/scielo.php?pid=S003476122011000500008\&script=sci_abstract\&tlng= $\mathrm{pt}>$ 
Silva, E.C. (2010). Governança corporativa nas empresas: guia prático de orientação para acionistas, executivos, gestores, analistas de mercado e pesquisadores. $2^{\mathrm{a}}$ ed. São Paulo. Atlas.

Silva, T.M. (2014). Teste t-Student: Teste de igualdade de variâncias. UFP-Universidade Federal do Pará. Belém, PA.

Terence, A.C. F. \& Escrivão Filho, E. (2006). Abordagem quantitativa, qualitativa e a utilização da pesquisa-ação nos estudos organizacionais. XXVI ENEGEP - ABEPRO. Fortaleza, CE. Out

Thiollent, M. (2009). Metodologia de Pesquisa-ação. São Paulo: Saraiva

Vieira, C.B. H., Verde, I.O.L., Bezerra, R.L., Rodrigues, P.N. \& Ismael, V.S. (2011). Índices de Rentabilidade: Um estudo sobre os Indicadores ROA, ROE de Empresas do Subsetor De Tecidos, Calçados e Vestuários, Listadas na Bovespa. - Convibra VIII Congresso Virtual Brasileiro - Administração. Disponível em:

<http://www.convibra.com.br/upload/paper/adm/adm_3052.pdf >.

Vinhado, F.S. (2010). Determinantes da rentabilidade das instituições financeiras no Brasil: uma aplicação em painel dinâmico. Universidade Católica de Brasília. Brasília/DF.

Disponível em: <https://bdtd.ucb.br:8443/jspui/handle/123456789/624>

\section{Porcentagem de contribuição de cada autor no manuscrito}

Ana Luísa Moreira Alves Barbosa-25\%

Isabela Lorrayni Deodato Pedreiro - $25 \%$

Laura Oliveira de Souza $-25 \%$

Willian Antônio de Castro - 25\% 